\section{Evaluation of patients' compliance to recall visits after tooth extraction at the Dental Centre, University of Benin Teaching Hospital (UBTH): A two-year retrospective study}

*Owen Stephen OMOROGBE, **Osazee kelvin ORHUE, ***Edorisiagbon OSAYANDE, [*Department of Oral and Maxillofacial Surgery, University of Benin Teaching Hospital, Benin City, Edo State, **Department of Family Dentistry, University of Benin Teaching Hospital, Benin City, Edo State ***Central Hospital Benin City, Edo State]

\section{Correspondence}

Dr. Owen Stephen Omorogbe

Department of Oral and Maxillofacial Surgery, University of Benin Teaching Hospital, Benin City, Edo State

Email:omorogbesteveo@gmail.com

\section{ABSTRACT}

Objective: This study aims to evaluate the level of patients' compliance with recall / follow-up visits attending the dental Centre of the University of Benin Teaching Hospital (UBTH).

Methods: This study adopted a descriptive retrospective study of case notes retrieved from the medical records department of the dental Centre, University of Benin Teaching Hospital. The period under study covers 2019 to 2021 . The data was collected by means of 1232 questionnaire and analyzed using descriptive statistics such as frequency and percentages.

Results: The result showed that the participants in the age bracket of 18-40 years of age (277) complied better to recall visit in comparison with the study age distributions which are 41-65 years (218) and age above 65 years (188). As per the influence of gender on compliance of patients with post-extraction recall visits, it was observed that the male participants (288) responded better to the recall visits compared to the female participants (251). The Relationship between distance away from the hospital and compliance of patients with post-extraction recall visits was also evaluated, and it was observed that the patients closer to the hospital within $5 \mathrm{~km}$ (442) complied better to recall revisit in comparison to the participants who were within $10 \mathrm{~km}$ (224) from the hospital as well as the participants that were $10 \mathrm{~km} \mathrm{\&} \mathrm{above}$ (17). Finally, the influence of interval between procedure and recall visit was also evaluated, and the result revealed that the participants that were given 7 days of recall revisit (663) complied better compared with the participants who were given 14days duration for recall revisit (478).

Conclusion: The data from this study highlighted the possible need for a paradigm shift in patient-doctor interphase especially as it concerns recall visits. Compliance to recall appointment by the patients depends largely on age, gender, distance from hospital and interval between procedures and is mainly responsible for the noncompliance of patients to recall visit.

Keywords: Patients' compliance to recall visits, Dental Procedure, and Patient's response.

Received: o8-Oct, 2021

Revision: 10 Nov, 2021

Accepted: 12 Nov, 2021

https://orcid.org/0000 $00030261325 X$
Osazee kelvin Orhue

Osazee kelvin Orhue

https://orcid.org/0000 000341438861

Edorisiagbon Osayande

https://orcid.org/0000 000226588768

Citation: Omorogbe OS, Orhue OK, Osayande E. Evaluation of patients' compliance to recall visits after tooth extraction at the Dental Centre, University of Benin Teaching Hospital (UBTH): A two-year retrospective study. Nig J

Dent Res 2022; 7(1):45-52 


\section{INTRODUCTION}

Tooth extraction is the most common procedure in oral surgery and dentistry. ${ }^{1}$ Compliance with postextraction instructions and adequate patient education given after oral surgical procedures can improve patients' satisfaction and decrease postoperative morbidity. ${ }^{2}$ In dentistry, written postsurgical instructions are presented at an intellectual level too high for the average patient to understand and eventually comply with. ${ }^{3}$ To enhance compliance, it is necessary for post extraction instructions to be simple and encoded in the language that the patient understands. ${ }^{3}$

The understanding and the subsequent implementation of post-operative instructions influence the recovery from any surgical procedure. ${ }^{4}$ Some authors state that instructing patients about post-operative care reduces post-operative morbidity and improves the quality of life during the recovery period. 4 Poor compliance of the patients is considered one of the main causes of post-operative complications. ${ }^{5}$ Several variables may interfere with the extent and quality of instructions; how the instructions are presented has a role in compliance among respondents. ${ }^{3}$

A body of scientific report has demonstrated the critical relationship between post-operative instructions and patients' compliance. Gheisari et al. ${ }^{6}$ and Omorodion and Osadolor ${ }^{3}$ in different studies revealed that patients who received verbal instructions as the mode of post-operative instructions reported most intense pain and least satisfaction, relative to patients who received both verbal and written instructions and were the most satisfied. ${ }^{3,6}$ Additionally, the study of Akpata et al. ${ }^{5}$ revealed that there was better compliance among patients placed on verbal instructions than those placed on written instructions. ${ }^{5}$

The postoperative period is also influenced by the understanding of the patient and the subsequent implementation of the guidelines presented by the professional in order to minimize morbidity, complications and to improve the quality of life of the patient. ${ }^{4}$ Clearly, the main elements that could interfere with the understanding of postoperative care instructions are how they are presented by the professional (verbally and/or written) and the sociocultural level of the patient. ${ }^{7}$ However, there are no references in the literature that consider how these two concepts may influence the adherence to postoperative instructions, ${ }^{8}$ or its possible correlation with the level of preoperative anxiety that is common in any surgical procedure.

The understanding and subsequent execution of postoperative guidelines are factors that affect the recovery from any surgical procedure. ${ }^{9}$ Therefore, the need for proper post-extraction instructions for adequate patients' compliance and reduced postoperative complications cannot be overemphasized. Going forward, a few studies have attempted to highlight the factors responsible for failed appointments with age, marital status, complexity of treatment, medical status, educational background, distance from clinic emerging as the most relevant factors. ${ }^{10,11}$ Currently there is sparse data concerning the level of patients' compliance with recall visits /follow up appointments in Nigeria despite its importance in the overall success of patient care; this has made it arduous to legislate for possible modes of intervention which would be aimed at ensuring better compliance of patients with follow-up appointments.

The foray into this aspect of patient care has become even more relevant in modern day practice because of its relationship with the level of patient appreciation and understanding of the treatment need as well as the degree of patient satisfaction with the endeavor of the caregivers'. Therefore, this study sought to evaluate the level of patients' compliance with recall / follow-up visits attending the dental Centre of the University of Benin Teaching Hospital (UBTH).

METHODOLOGY This study is a descriptive retrospective study using case notes retrieved from the medical records department of the dental Centre, University of Benin Teaching Hospital. The case notes spanned from the current year and date back to 2019. The data was collected by means of a questionnaire applied to 1232 cases.

\section{Method of Data Analysis}

The data collected was statistically analyzed using IBM SPSS Version 22 for descriptive statistics.

Socio-demographic information of the participants was examined and the result (table 1 ) revealed that from a study population 1232 participants, the age was found to be distributed as follows; $42 \%$ of the 
study population was aged $18-40$ years, 33\% (41-65 years) and $25 \%$ of the study population were above 65 years. As per the variable sex; $44 \%$ were male and $56 \%$ female. Businessmen/women and civil servants were found to be the dominant population (25\%) in respect of occupation. Students followed with $23 \%$, retirees $(19 \%)$ and the artisans were found to be the least with $8 \%$. The distance of the participants away from the hospital was also evaluated, and the result revealed that the participants within $5 \mathrm{~km}$ (52\%) from the hospital were dominant in population followed by within $10 \mathrm{~km}$ (39\%) and only $9 \%$ of the participants were $10 \mathrm{~km}$ and above away from the hospital Table 1: Showing sociodemographic information of the participants

Figures 1 and 2 show the complaints registered by the participants as well as the compliance of the participants to revisit call. The complaints were found to be distributed as follows; tooth pain (56\%), fracture $(11 \%)$, pericoronitis (10\%), gross caries ( $8 \%)$, orthodontic $(5 \%)$, and extra teeth $(4 \%) .55 \%$ of the 1232 of the participants complied to recall visit while $45 \%$ did not comply to recall visit.

Figure 3: Showing the influence of age on compliance of patients with post-extraction recall visits

The result of the influence of age on compliance of patients with post-extraction recall visits (figure 3 ) revealed that the participants in the age bracket of 18-40 years of age (277) complied better to recall visit relative to the other study age distribution 41-65 years (218) and above 65 years (188).

Figure 4 Show the influence of gender on compliance of patients with post-extraction recall visits. The result show that the male participants (288) responded better to the recall visits relative to the female participants (251).

Figure 5: Showing influence of location (distance) on compliance of patients with post-extraction recall visits

The result on influence of location (distance) on compliance of patients with post-extraction recall visits (figure 5) revealed that the participants (442) within $5 \mathrm{~km}$ from the hospital complied better to recall revisit in comparison to the participants (224) who were found to be within 10km away from the hospital as well as the participants (17) that were $10 \mathrm{~km}$ and above.

Figure 6: Showing the influence of interval between procedure and recall visit

Finally, the influence of interval between procedure and recall visit was also evaluated, and the result (figure 6 ) revealed that the participants (663) that were given 7 days of recall revisit complied better relative to the participants (468) who were given 14 days duration for recall revisit (478).

Table 1: Showing sociodemographic information of the participants

\begin{tabular}{ccc}
\hline Variables & Frequency & Percentage \\
\hline Age (Years) & & \\
$18-40$ & 523 & 42 \\
$41-65$ & 406 & 33 \\
Above 65 & 277 & 25 \\
Sex & & \\
Male & 539 & 44 \\
Female & 693 & 56 \\
Occupation & & 23 \\
Students & 280 & 8 \\
Artisans & 93 & 25 \\
Business & 314 & 25 \\
Civil Servants & 307 & 19 \\
Retired & 238 & \\
Distance from Hospital & & 52 \\
Within 5km & 644 & 39 \\
Within 10km & 477 & 9 \\
10km \& Above & 111 & \\
\hline
\end{tabular}




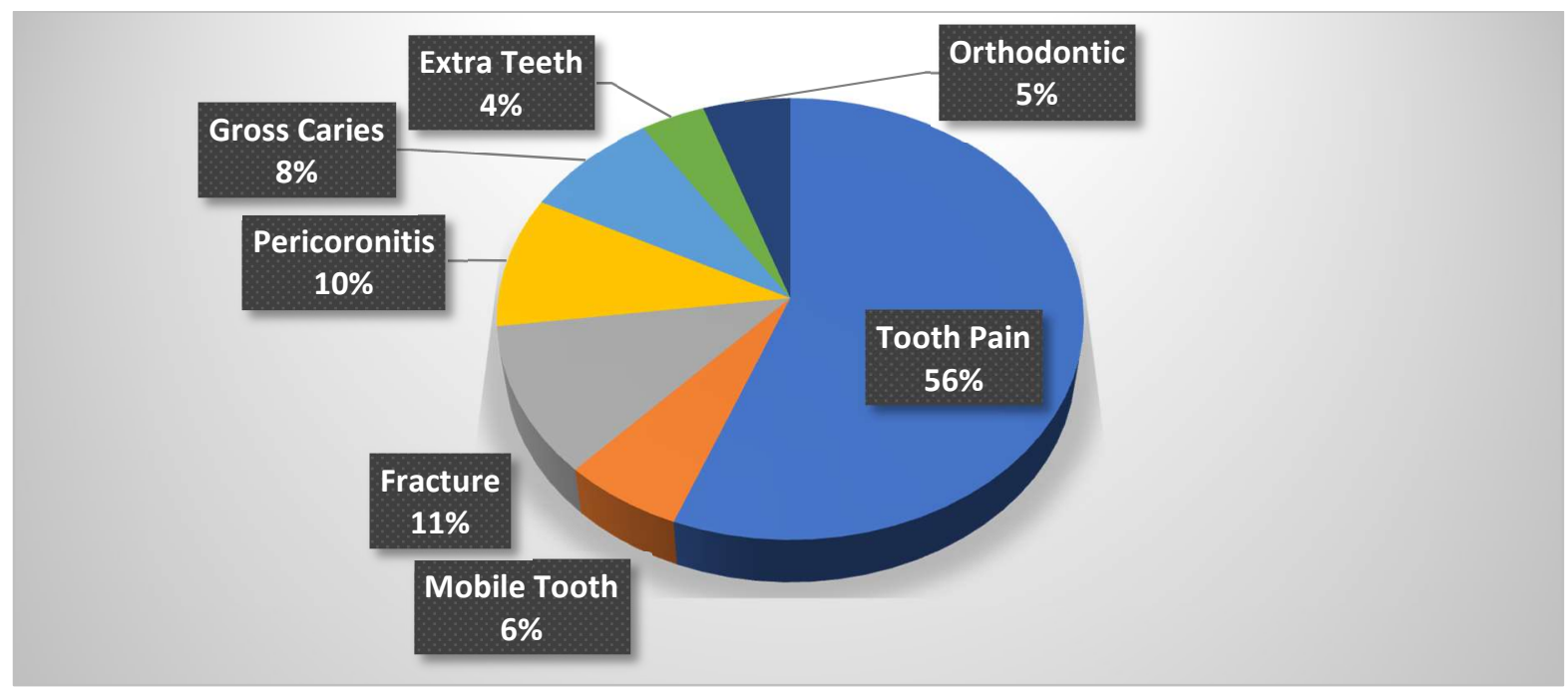

Figure 1: Showing complaint of the participants

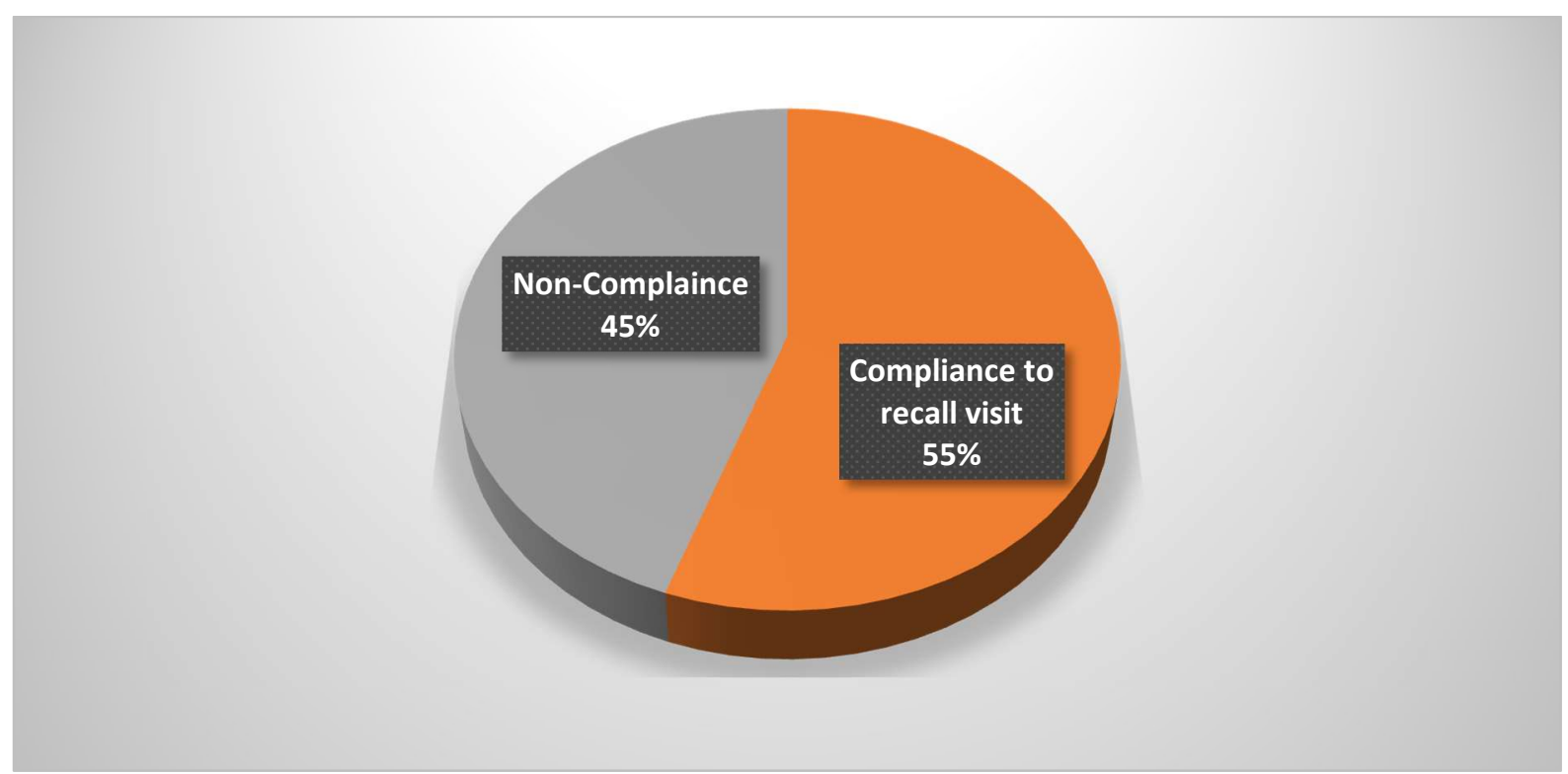

Figure 2: Showing compliance of the participants 


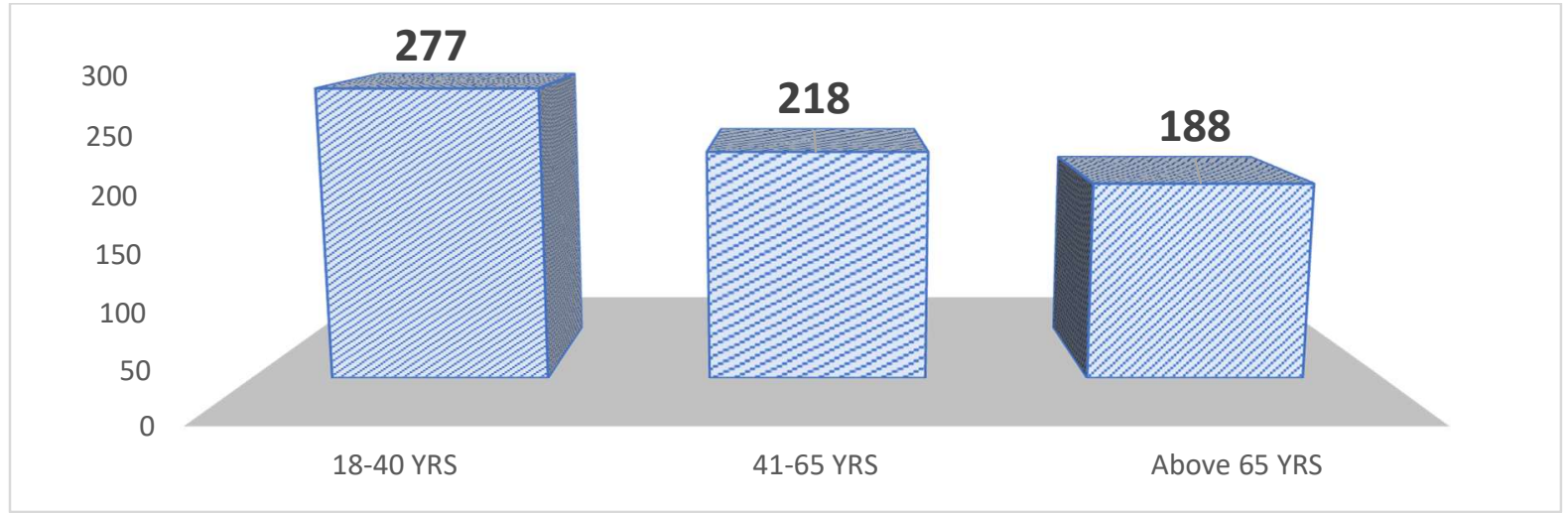

Figure 3: Showing the influence of age on compliance of patients with post-extraction recall visits

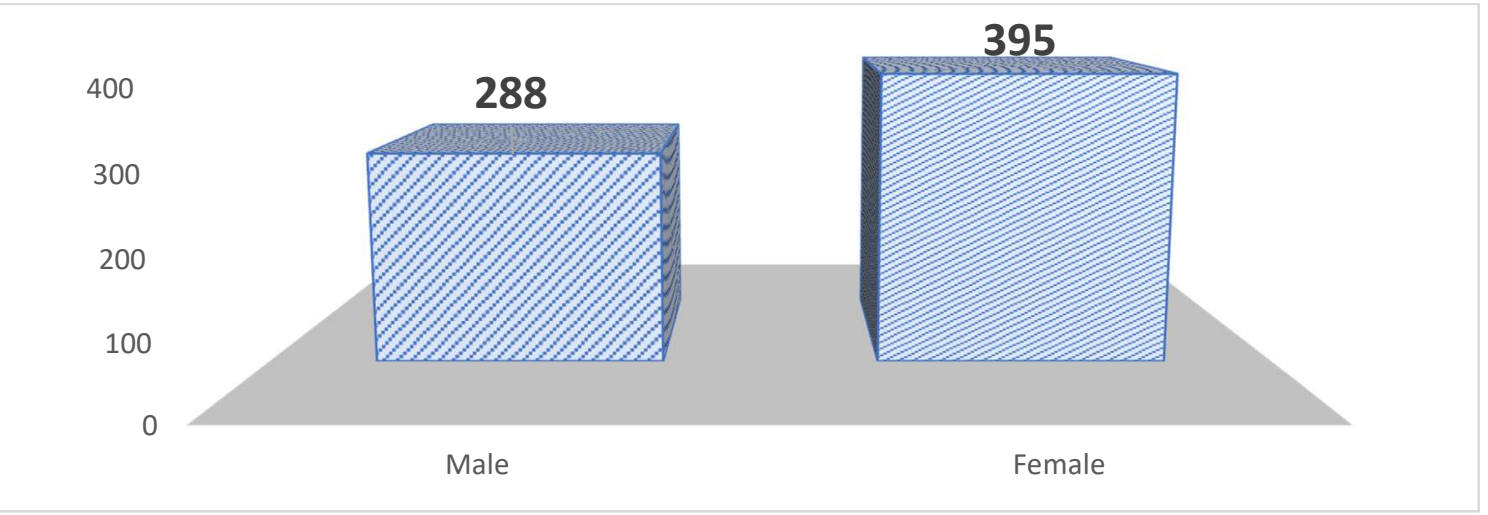

Figure 4: Showing the influence of gender on compliance of patients with post-extraction recall visits

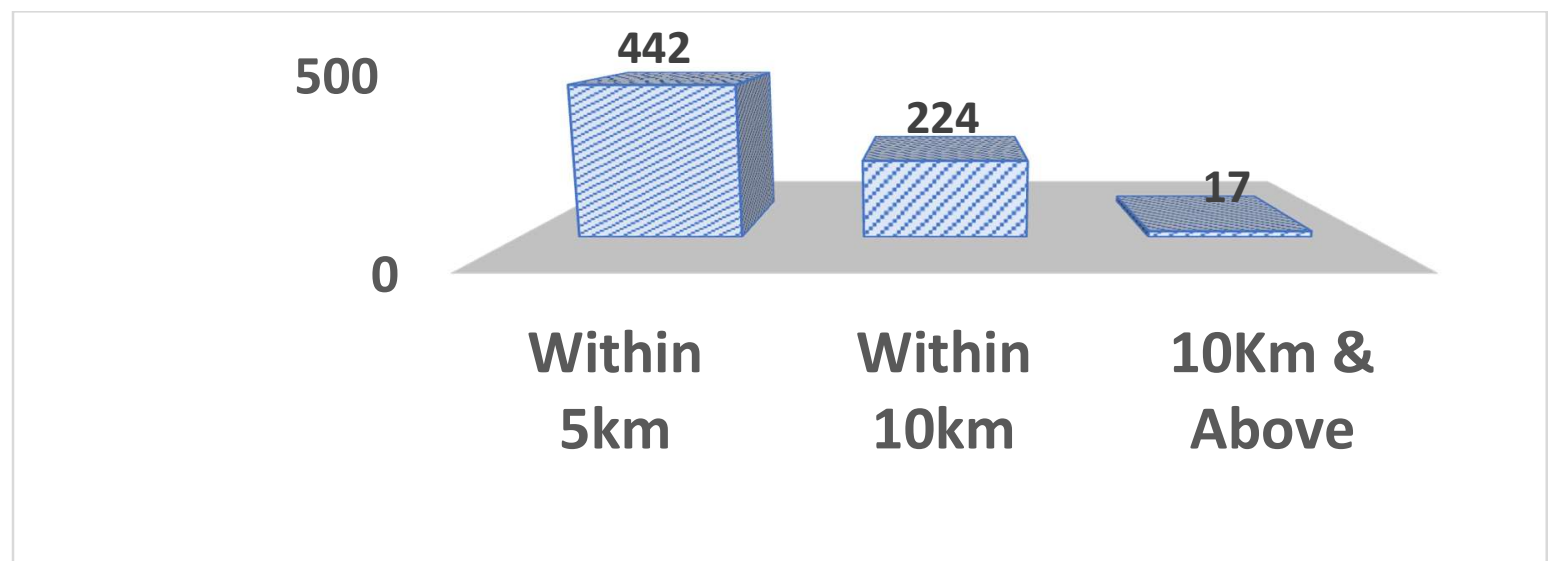

Figure 5: Showing influence of location (distance) on compliance of patients with post-extraction recall visits 


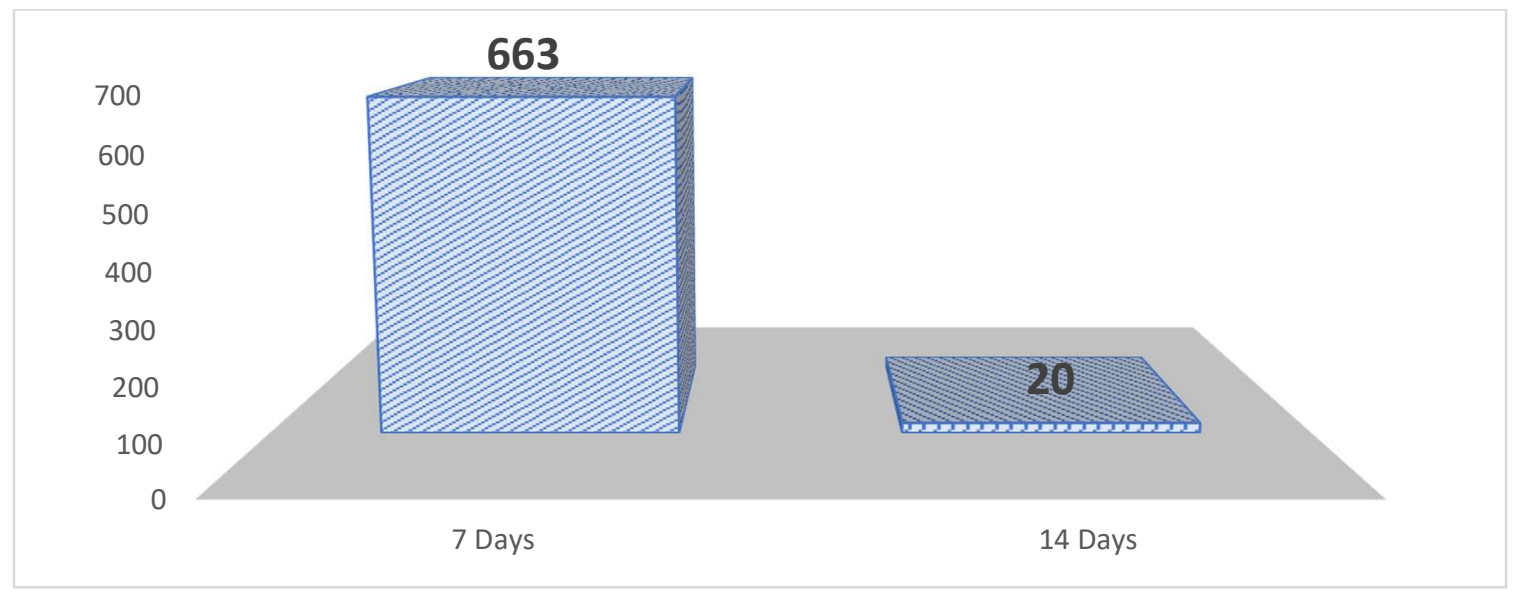

Figure 6: Showing the influence of interval between procedure and recall visit

\section{DISCUSSION}

A body of scientific reports in the medical, pharmaceutical and nursing disciplines has demonstrated that non-compliance or poor compliance is one of the greatest problems in health care resulting in derisory quality of life of the patient. ${ }^{2,12}$ According to Bunzel and LederachHofmann (2000), compliance is largely regarded as the term for patient co-operation with clinical prescriptions, which is vital for therapeutic success. ${ }^{13}$ The postoperative period is also influenced by the understanding of the patient, and the subsequent implementation of the guidelines as presented by the professional; in order to minimize morbidity, and to improve the quality of life of the patient. ${ }^{4}$

Currently there is sparse data concerning the level of patients' compliance with recall visits /follow up appointments in Nigeria despite its importance in the overall success of patient care. Therefore, this study examined the level of patient compliance with recall / follow-up visits by patients attending the Dental Centre of the University of Benin Teaching Hospital (UBTH).

Socio-demographic information of the participants was examined and the result showed that from a study population of 1232 participants, the age distribution was as follows; $42 \%$ of the study population was aged $18-40$ years, 33\% (41-65 years) and $25 \%$ of the study population were above 65 years. As regards the variable, sex; $44 \%$ was male and $56 \%$ (female). Business and civil servants were found to be the dominant population $(25 \%)$ in respect of occupation. Students followed with $23 \%$, retirees
$(19 \%)$ and the artisans were found to be the least with $8 \%$. The distance of the participants away from the hospital was also evaluated, and the result revealed that the participants within $5 \mathrm{~km}(52 \%)$ from the hospital were dominant in population followed by within $10 \mathrm{~km}(39 \%)$, and only $9 \%$ of the participants were $10 \mathrm{~km}$ and above away from the hospital. The nature of complaints registered was also examined and the complaints were found to be distributed as follows; tooth pain (56\%), fracture (11\%), pericoronitis $(10 \%)$, gross caries $(8 \%)$, orthodontic $(5 \%)$, and supernumerary teeth ( $4 \%)$.

Studies over several decades have consistently found that patients do not correctly recall much of the recommendations and information given by their physicians; and this results in poor compliance to recall visit. ${ }^{14,15,16}$ In the present study, it was found out that $55 \%$ of the 1232 of the participants complied to recall visit appointments while $45 \%$ did not comply. In an attempt to corroborate the finding with existing literature, it was observed that there is currently no available literature in Nigeria that has reported similar result. However, the study of Oluwole et al. ${ }^{17}$ reported that a positive association exists between treatment satisfaction and adherence to recall visit appointment among hypertensive patients. ${ }^{17}$

A few studies around the world have associated the factors responsible for failed appointments with age, marital status, complexity of treatment, medical status, educational background, and distance from clinic emerged as the most relevant factor. ${ }^{10,11}$ According to Yuasa et al. ${ }^{18}$ all these factors could be obstacles to the proper adherence to postoperative 
instruction for the patient during the recovery period. ${ }^{18}$ Hence the present study evaluated the influence of some factors including age, gender, location and interval between procedure and recall visit on compliance of patients with post-extraction recall visits. $55 \%$ of the study of population who complied to recall visits was used for further evaluation.

The result of influence of age on compliance of patients with post-extraction recall visits revealed that the participants in the age bracket of 18-40 years of age (277) complied more with recall visit compared to the other study age distribution $41-65$ years (218) and above 65 years (188). As per the influence of gender on compliance of patients with postextraction recall visits, it was observed that the male participants (288) responded better to the recall visits relative to the female participants (251). The association of distance of the patient to the hospital and compliance of patients with post-extraction recall visits was also evaluated, and it was observed that the patient (442) closer to the hospital (within $5 \mathrm{~km}$ ) complied more with recall revisit in comparison to the participants (224) who lived within $10 \mathrm{~km}$ from the hospital; as well as the participants (17) who lived $10 \mathrm{~km}$ and above. Finally, the influence of intervals between procedure and recall visit was also evaluated, and the result showed that the participants (663) that were given seven days of recall revisit complied better than the participants (478) who were given fourteen days for recall revisit.

There is currently no existing literature in Nigeria that has considered how the evaluated factors in the present study associate with compliance of patients with post-extraction recall visits. Clearly and as revealed in the present study, factors including age, gender, patient location and interval between procedure and recall visit are positively associated with compliance of patients to post-extraction recall visits appointments.

\section{CONCLUSION}

The data from this study highlights the possible need for a paradigm shift in patient-doctor interphase especially as it concerns recall visits. Compliance to recall visits by the patients depends largely on age, gender, location and interval between visits.

\section{REFERENCES}

1. Akinbami BO, Godspower T. Dry socket: incidence, clinical features, and predisposing factors. International Journal of Dentistry. 2014; 796102. PMID: 24987419.

2. Adebayo ET, Dairo M. Patients ' compliance with instructions after oral surgery in Nigeria. Journal of Community Medicine \& Primary Health Care. 2005; 17: 38-44.

3. Omorodion GI, Osadolor AJ. Dental patients' compliance with post-extraction instructions at a Secondary Health Care Facility in Nigeria. Yenagoa Medical Journal.2021; 3: 158-165.

4. Alvira-González J, Gay-Escoda C. Compliance of postoperative instructions following the surgical extraction of impacted lower third molars: a randomized clinical trial. Medicina Oral, Patología Oral y Cirugía Bucal. 2015; 20: e224e230.

5. Akpata O, Omoregie OF, Owotade F. Alveolar Osteitis: Patients' compliance to post-extraction instructions following extraction of molar teeth. Nigerian Medical Journal. (2013); 54: 335-338.

6. Gheisari R, Resalati F, Mahmoudi S, et al. Do Different Modes of Delivering Postoperative Instructions to Patients Help Reduce the Side Effects of Tooth Extraction? A Randomized Clinical Trial. Journal of Oral Maxillofacial Surgery. 2018; 76: 1652.e1-1652.e7.

7. Kessels RP. Patients' memory for medical information. Journal of the Royal Society of Medicine. 2003; 96: 219-222.

8. Susarla SM, Dodson TB. Estimating third molar extraction difficulty: A comparison of subjective and objective factors. Journal of Oral Maxillofacial Surgery. 2005; 63: 427-434.

9. Faheem S. Patients Compliance and Follow-Up Rate after Tooth Extraction. IOSR Journal of Dental \& Medical Science. 2017; 16: 115-120.

10. Albarati SF. Apointments failure among female patients at a dental school clinic in Saudi Arabia. Journal of Dental Education. 2009; 73: 1118- 1124

11. George AC, Hoshing A, Joshi NV. A study of the reasons for irregular dental attendance in a private dental college in a rural set up. Indian Journal of Dental Research. 2007; 18: 78-81 
12. Adebayo E., Sotunde T, Umeh N. Oral health status of a Nigerian military population. Nigerian Dental Journal. 2002; 1: 7-10.

13. Bunzel B, Laederach-Hofman K. Solid organ transplantation: are there predictors for posttransplant non-compliance? A literature overviews. Transplantation. 2000; 70: 711-716.

14. Laws $M B$, Lee $Y$, Taubin $T$, et al. Factors associated with patient recall of key information in ambulatory specialty care visits: Results of an innovative methodology. PLoS ONE. 2018; 13: eo191940.

15. Bravo BN, Postigo JML, Segura LR, et al. Effect of the evaluation of recall on the rate of information recalled by patients in Primary Care. Patient education and counseling. 2010; 81: 272274 .
16. Jenkins $V$, Solis-Trapala I, Langridge $C$, et al. What oncologists believe they said and what patients believe they heard: an analysis of phase I trial discussions. Journal of Clinical Oncology. 2011; 29: 61-68.

17. Oluwole EO, Osibogun O, Adegoke O, et al. Medication adherence and patient satisfaction among hypertensive patients attending outpatient clinic in Lagos University Teaching Hospital, Nigeria. Nigerian Postgraduate Medical Journal, 2019; 26: 129-137

18. Yuasa H, Kawai T, Sugiura M. Classification of surgical difficulty in extracting impacted third molars. British Journal of Oral Maxillofacial Surgery, 2002; 40: 26-31. 